\title{
School bullying and fitting into the peer landscape: A grounded theory field study
}

Robert Thornberg

The self-archived postprint version of this journal article is available at Linköping University Institutional Repository (DiVA):

http:/ / urn.kb.se/ resolve?urn=urn:nbn:se:liu:diva-140827

N.B.: When citing this work, cite the original publication.

This is an electronic version of an article published in:

Thornberg, R., (2018), School bullying and fitting into the peer landscape: A grounded theory field study, British J ournal of Sociology of Education, 39(1), 144-158.

https:// doi.org/ 10.1080/ 01425692.2017.1330680

Original publication available at:

https:// doi.org/ 10.1080/01425692.2017.1330680

Copyright: Taylor \& Francis (Routledge) (SSH Titles)

http:// www.routledge.com/ 


\title{
School bullying and fitting into the peer landscape: a grounded theory field study
}

\begin{abstract}
Research on school bullying has its roots in the field of developmental and educational psychology, and appeals to the need for a theoretical and methodological widening in order to grasp its ambiguity and complexity. The article draws on ethnographic fieldwork in which 144 pupils and seven teachers participated from seven school classes in three Swedish public primary schools. A constructivist grounded theory guided data gathering and analysis. This paper offers an interpretative portrayal of school bullying. It paints a picture of the core process of misfitting and how this process involves the selective use of normativities from the macro-, meso- and micro-level. When bullying is conceptualized as simply caused by individual characteristics, teachers and others become blind to gender norms, heteronormativity, racism and a range of other oppressions taking place in bullying, and it will fail to offer an appropriate knowledge base on how to counteract and reduce bullying.
\end{abstract}

Keywords: bullying; misfitting; normativity; intersectionality

\section{Introduction}

School bullying could be defined as a social process in which a child in a less powerful position is repeatedly offended, harassed or excluded by others (Salmivalli 2010). Research on school bullying has its roots in the field of developmental and educational psychology, and therefore individual psychological perspectives have been commonly used in the mainstream school bullying literature. Reducing our understanding of bullying to pathological or deficient individual and family factors has, however, attracted critical voices from sociologists and other scholars who emphasize the importance of analyzing the school and peer context, social interaction patterns, culture norms, power, discourses, ethnicity, gender, sexuality, etc. (see for example, Bansel et al. 2009; Schott and Søndergaard 2014; Renolds 2006; Ringrose 2008; Søndergaard 2012). At the same time, there is a growing interest among developmental and educational psychologists in examining bullying in relation to contextual factors and social processes (e.g. Hong and Espelage 2012; Salmivalli 2010). School bullying is a complex social phenomenon, requiring the need for a theoretical widening in order to grasp its ambiguity and complexity (Horton 2016b; Schott and Søndergaard 2014; Thornberg 2015b). As highlighted by Søndergaard (2012, 357), 'in recent years an increasing number of researchers have called for sociological and social psychological analysis of the phenomenon', which is the very intention of this study.

Furthermore, research on bullying has usually been conducted by quantitative methods based on questionnaires and psychometric measurements (for reviews, see Jimerson, Swearer, and Espelage 2010). Bosacki, Marini, and Dane (2006, 232) argue that, although quantitative research provides a great deal of critical information about bullying, it 'does not give children an opportunity to discuss their own understanding of bullying in their own voices'. In contrast, qualitative research is, as Mishna Saini and Solomon $(2009,1222)$ have put it, 'capable of discovering important discourses and nuances' that would be missed in large-scale survey studies. It provides opportunities to study bullying as social processes, interactions and meaning-making in the everyday context of particular settings. And, as Bosacki Marini, and Dane (2006) claim, it gives participants opportunities to discuss their own understanding and experiences in their own voices. Horton (2011) argues that investigating bullying as an interactive social process requires additional ethnographic studies. In the present qualitative study, I have employed ethnographic fieldwork (e.g. Hammersley and Atkinson 2007; Schatzman and Strauss 1973) guided by grounded theory methods (e.g. Charmaz 2014; Glaser and Strauss 1967) in order to investigate the social dynamics of school bullying. 


\section{Theoretical framework}

The current study adopts a social-ecological perspective on bullying (Espelage and Swearer 2004; Hong \& Espelage 2012; Thornberg 2015b), which states that bullying has to be understood as a social phenomenon that is established and perpetuated over time as the result of the complex interplay between the individual and contextual factors. Although the socialecological theory includes several systems, the main focus in the current study was on the microsystem (peer ecology in the school classes) and the interplay among microsystem and macrosystem (cultural norms, social categories, power structures, and ideologies). In the current study, I have adopted a recent sociological theoretical development called the modified ecological model in which the social-ecological theory has been integrated with symbolic interactionism (Migliaccio and Raskauskas 2015) and the new sociology of childhood (Migliaccio 2015).

In line with a symbolic interactionist perspective (Blumer 1969; Hewitt and Shulman 2011), I have assumed the power imbalance associated with bullying as situated and relational, and thus constituted and manifested in everyday social interactions in children's positioning and relational work, rather than personal and located in individuals (Thornberg 2015b). At the same time, the modified ecological model (Migliaccio 2015; Migliaccio and Raskauskas 2015) emphasizes 'negotiated order' (cf. Strauss 1978) that relies on each level of the system. Children are considered as active social agents in the development of their own culture as well as in the continuance, or even challenge of the larger culture (Corsaro 2005; Prout and James 1997). Thus, power derives from multiple sources, and is not solely decided by cultural determinants or isolated social interactions. There is a complex interplay. Although it is reflected by what is important in the wider culture, individuals do not have power unless acknowledged by others through social interactions. The modified ecological model acknowledges and embraces both agency and structure.

\footnotetext{
Bullying is larger than just the relationship between bully and victim. That relationship is embedded within layers of social forces that create the culture that generates the opportunity for bullying to occur. These social forces work together to produce, and reproduce a bullying culture by defining and maintaining paths to power among students. (Migliaccio and Raskauskas 2015, 30)
}

The aim of the analysis presented in this paper was to investigate school bullying as a social phenomenon, from the culture, main concerns, and perspectives of children, and to construct a grounded theory on school bullying as a social process.

\section{Methods}

The article draws on ethnographic fieldwork in three public primary schools located in urban neighbourhoods of different socioeconomic statuses in a medium-sized Swedish city - the first school in a white, predominantly middle-class catchment; the second school in a mixed ethnic but majority white, working-class and middle-class catchment; and the third school in a socially disadvantaged, multi-ethnic and white minority working-class catchment. I spent 1-3 days a week in 4-6 months with each class. In total, 144 pupils (70 boys and 74 girls) from seven school classes (four classes in Grade 4 and three classes in Grade 5) participated together with seven teachers. In Sweden children usually begin in Grade 4 the year they become 10 years old, and Grade 5 the year they turn 11. Informed consent was given by teachers, children, and parents. ${ }^{1}$

\footnotetext{
${ }^{1}$ A first report of the ethnographic project was presented in Author (2015) but after that publication, two additional school classes from a new school have been included.
} 
Field observations of everyday interactions between the pupils, and between them and their teachers, as well as informal conversations and qualitative interviews with pupils and teachers in each class were the main data collection methods. Field notes and transcripts of audio recordings built up the data. I explored and analysed both short-term and long-term bullying. Eight cases of long-term bullying, in which the victims had been bullied for more than a year and were still being bullied during the study, were identified. More than 20 shortterm bullying cases, in which the victims had been bullied for a couple of weeks or months, were examined and compared with the long-term bullying cases. Temporary or more chronic 'bullies' and 'victims' were identified in the ethnographic fieldwork, particularly by the recurrent patterns of reports from children during my informal conversations with them, but also by field observations. Hence, 'bullies' are in the present study defined as those who were identified by peers as those who repeatedly harassed their victim. 'Victims' in turn are here defined as those who were identified by peers as those who were repeatedly targets of bullying or peer harassment. ${ }^{2}$

Many childhood researchers and school ethnographers emphasize the value of taking an atypical, less power-oriented adult research role. In line with that approach, I consciously assumed a 'least-adult role' (Mandell 1991), avoided positions of authority and went through the day-to-day school life with or near the children, including the adoption of a nonjudgmental approach. I also told the children at the beginning of the fieldwork that I would not act as a teacher or someone in charge, but more as a guest who wanted to know how school life works, what it is like to be a current pupil in school, and why teasing and bullying sometimes happens in school. In accordance with the new sociology of childhood, I approached and treated the children as the main informants and competent commentators on their own lives as pupils in school (Prout 2002). However, adopting a 'least-adult role' was not completely unproblematic, and I occasionally deviated from this position due to ethical considerations. Like Horton (2012), I decided to intervene if I judged that a student was at risk of being physically injured or appeared visibly distraught.

The fieldwork and analysis were guided by grounded theory (GT) methods (Glaser and Strauss 1967) based on a constructivist position (Charmaz 2014). During my fieldwork, I constantly moved between data collection and analysis guided by theoretical sampling, which Glaser and Strauss $(1967,45)$ define as 'the process of data collection for generating theory whereby the analyst jointly collects, codes and analyses his data and then decides what data to collect next and where to find them, in order to develop his theory as it emerges'. GT methods (e.g. Charmaz 2014; Glaser 1978) were used to analyse data: coding (creating qualitative codes and categories grounded in data), constant comparison (comparing data with data, data with codes, codes with codes, and so on), memo writing (writing down ideas about relationships between codes and other theoretical ideas that came to mind during the coding), and memo sorting (comparing and sorting memos).

During the first step of coding (initial coding), I tried to remain open to exploring whatever theoretical possibilities I could discern in the data. I developed codes by constantly comparing data with data, data with codes and codes with codes. I was also guided by an array of analytical questions (see Charmaz 2014; Glaser 1978), including the following: What is happening in the data? What is going on? What are the main concerns faced by the participants in the action scene? What do the data suggest? What category does this incident indicate? During the next step of coding (focused coding), I used the most significant and frequent initial codes to sift through the large amounts of data. The focused codes I generated

\footnotetext{
2 Although the terms 'bully' and 'victim' are used in the study because they are used by the participants, labelling children as 'bullies' or 'victims' is problematic and has to be avoided in the school practice. For a further discussion, see my conclusion section.
} 
in this phase were now more selective and conceptual than the initial codes. Data collection, coding and analysis were guided by these focused codes. In parallel with focused coding (Charmaz 2014), I began to conduct theoretical coding (Glaser 1978). I explored and analysed how the empirical codes were related to each other and integrated them into a GT by using theoretical codes, which refer to underlying logics or patterns embedded in pre-existing theories in many areas. Moreover, during the analysis, pre-existing theoretical concepts from literature, such as labelling, performativity, normativities, and intersectionality were used as 'lenses' and tools that helped me to focus my attention on certain phenomena, aspects and nuances, very much in line with the logic of abduction (Thornberg 2012). Like the theoretical codes that I used, these pre-existing concepts earned their way into the analysis by their fit and relevance.

\section{Fitting into the Peer Landscape}

The children in the current study were in general concerned with fitting into the peer landscape in their everyday school life. When I asked them about what they like most in school and what they thought really meant something for them in school, being with friends was one of the most common replies. Here are some of the pupil voices. 'What I like most in school is to be with all my friends' (Oscar, Grade 4). 'I think everyone would like to have friends. I wouldn’t like to go to school if I haven’t got any friends here' (Lisa, Grade 5). 'To me, the most important thing is to be with my friends' (Hannah, Grade 5). Although school breaks were the most salient arena in which to socialize and interact with friends and other peers, in several classroom observations I found children creating opportunities to socialize with each other, even though they were supposed to focus on schoolwork and not on talking. When I asked them about what they thought would be the worst thing that could happened them in school, recurrent answers were being alone, having no one to be with, having no friends or losing friends, being excluded and bullied. This fear can be associated with what Søndergaard (2012) conceptualizes as social exclusion anxiety, which she argues is potentially a shared affect by members of a group or community.

It is a fear that smoulders beneath the surface when people interact. Whenever people expect, or are expected to, become members of groups or communities ... the possibility arises that an individual's membership may be questioned. Individuals may experience insecurity about whether they legitimately belong to a particular group, or fear exclusion and marginalisation. (Søndergaard 2012, 360)

Social exclusion anxiety and its fear of social death (Søndergaard 2012) became salient among the children when we talked about their fears and worries about school.

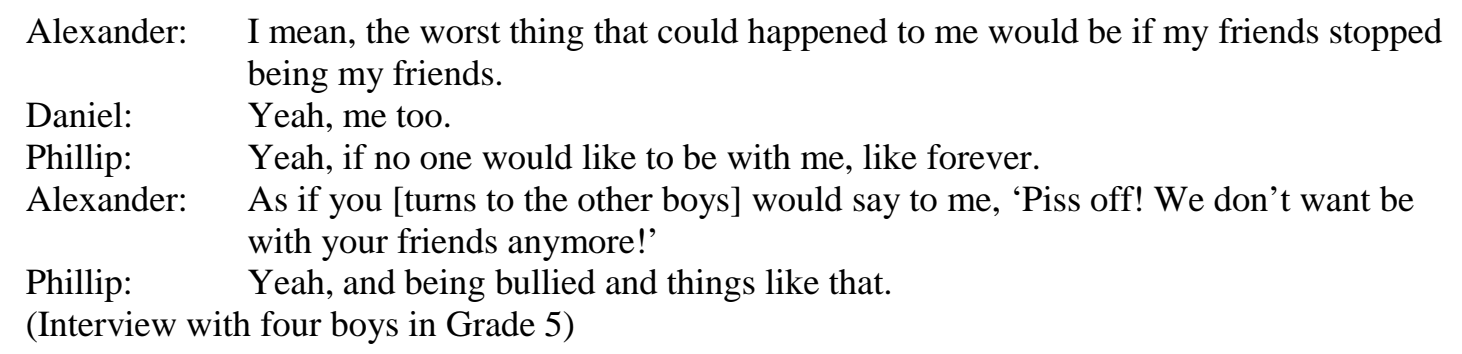

Thus, the children expressed a strong concern of friendship and social belonging. The peer landscape, in turn, was structured around two basic axes - a vertical axis of social status or hierarchy and a horizontal axis of closeness or friendship. The pupils were strikingly aware of the various groups or dyads of friends as well as who in their school class was more popular, who was less popular and who was in between. Fitting into the peer landscape was a social 
process that resembles what Blumer (1969) conceptualizes as joint action. He argues that 'human group life consists of, and exists in, the fitting of lines of actions to each other by the members of the group' (16-17). However, fitting into the peer landscape was not only about the fitting of lines of actions, but about the whole social process of fitting into social relations, friendships and hierarchies, which in turn produced and reproduced the dynamic and changeable structures of the peer landscape, as what Strauss (1978) conceptualized as negotiated order.

\section{The core process of misfitting in bullying}

The basic social process of the peer landscape in school did not only involve fitting but also misfitting, like two sides of the same coin. Misfitting is a social interaction pattern in which a peer is constructed as a person who does not fit in with the current others. Misfitting was the core process of bullying, as it socially defined, constituted or constructed the target pupil as 'odd', 'different' or someone who 'didn't fit it'. This strong theme in bullying has also been found in other studies (e.g. Bibou-Nakou et al. 2012; Teräsahjo and Salmivalli 2003; Thornberg 2010). As I have reported in an earlier report of this study (Author 2015), I found that the participants in long-term bullying often used dehumanising and deviant-constituting labels like 'moron', 'weird', 'ugly', 'retarded', 'nerd', disgusting', 'stupid', and 'stinking' to address their victims. The message to all involved was that the victim was not like us, but a deviant peer who did not fit into, and thus, was not worthy to belong to our peer dyad or group.

\footnotetext{
Robert: $\quad$ How come that you bully John? Help me understand!

Martin: We don't like him.

Robert: $\quad$ You don't like him?

Alexander: No, like when we are playing football, you don't want to have him on your team.

Martin: $\quad$ Yeah, he's so clumsy. Like missing the ball and running slowly all the time.

Alexander: Yeah, and he's weak, and has these disgusting rashes.

Martin: $\quad$ There are several kids who're bullying him because he's short and has rashes.

Alexander: They think he is ugly and odd.

(Interview with two boys identified as ‘bullies’ by their teacher and classmates, in Grade 5)
}

Like John, who had been bullied since the first grade, all long-term victims in the current study had a history of being repeatedly constructed as deviant by their peers. In every case of long-term bullying, the pattern was clear: The victims had the lowest or among the lowest status, and the identified bullies often belonged to high status groups. This association between social hierarchy and bullying, in which victims are at the bottom of the social hierarchy, are stigmatized and socially constructed as different, odd or deviant, has also been found in previous ethnographic studies (Adler and Adler 1998; Dixon, Smith, and Jenks 2004; Eder, Evans, and Parker 1995). Followers from middle and low status groups could also join long-term bullying as a result, for instance, of protecting themselves (e.g. 'It's wrong, but if I don't join them [the bullies] they might start bullying me too', Hanna in Grade 5; 'I'm happy it's not me', Liam in Grade 4) and peer pressure (e.g. 'Because everyone else does it', Fredric in Grade 4), and thus to strengthening their own fitting into the peer landscape by participating in the victim's misfitting.

Misfitting was not only the core process of long-term bullying, but in more short-term bullying as well. For example, when Sara came as a new classmate at the beginning of fourth grade, she strongly opposed the high-status boys Robin, Said and Felix when they harassed and teased other girls, including herself. When they picked on her, she name-called and teased them back. The boys started to bully Sara more systematically. They talked about her as 'cocky', 'boyish' and that she should not act as a boy (tough, aggressive, cool, cocky, mean), 
but as a girl (kind, nice, calm). After about a month, Sara began to change her approach, started to be more 'girlish' and get some allies of quite high status girls. The bullying faded. In one of the fifth-grade classes, Lisa and Elin were best friends and used to hang around with each other, alone or together with some other girls. One of these other girls, Julia, became more interested in Elin and tried to be a close friend by doing things like inviting her to come to her home and seeking her company a lot. Lisa reacted by defending her and Elin's friendship. She told Elin that Julia was trying to destroy their best friendship and that Julia was false and untrustworthy. The message was clear: Julia had negative characteristics and she did not fit in. Elin managed to influence Lisa and they started to be mean toward Julia, such as repeatedly giving her negative comments and excluding her during a couple of weeks. As a result, Julia stopped hanging around Lisa and Elin and began to socialize with some other girls. The short-term bullying stopped then.

In the analysis of bullying cases, it became clear to me that bullying served consistently to distinguish between 'fitted' and 'misfitted' pupils, and thus between 'normal' and 'deviant' pupils, resulting in included and excluded pupils. Bullying functioned like a self-serving and socially including ritual in which those who participated manifested and maintained their shared 'normality' by producing and reproducing the victim as different, odd, or 'not like us'. Thus, misfitting in bullying always involved an interplay between social positioning and social categorizing, which labelled and sorted the victims into out-group social categories, and where this 'otherness' was devalued and rejected (cf. Tajfel 1978). Misfitting can be associated with performativity, as it is defined by Butler (1993, xii), as the 'reiterative power of discourse to produce the phenomena that it regulates and constraints'. By repeatedly citing cultural and social norms, the pupils made them appear to be natural and necessary. At the same time, the appearance, style or the behavioural habit of the victim was constituted as outside the bounds of 'cultural intelligibility' (Butler 1990). In my further analysis, I will demonstrate how bullying is political as it (re)produces and naturalizes oppressive hegemonic discourses that marginalize, dehumanize and exclude those who fail to fit in.

\section{Selective use of normativities and the fluid co-construction of intersectionality}

Anna in Grade 4 had been bullied since Grade 2. According to both her and her classmates, it began when some of the boys in her class started to tease her and say mean things about her physical appearance. When I asked her how come these guys were bullying her, she immediately told me, 'it's because I'm fat'. Other peers in her class, including those identified in school as the bullies, gave me the very same explanation. She was bullied because she was 'fat', and - often added - 'ugly'. 'They tease and bully her because she is fat. That's not okay, but that's why. They think she is fat and ugly' (Therese, Grade 4). In this bullying case, obesity was socially constructed and perceived as being something abnormal and disgusting. Labelling Anna in this way made her an outsider, someone associated with 'otherness', a member of a devaluated out-group, and therefore someone who did not deserve to belong to any in-group of the class, even though she tried. Dominating discourses on health and obesity in the West have produced a fat-phobic society that tends to socially marginalize, discriminate, and stigmatize obese people (Lupton 2013), and previous research has found that obese children and adolescents are at a higher risk of being a target of bullying (Weunstock and Krehbiel 2009).

Anna in Grade 4 and Evelina in Grade 5 were both victims of long-term bullying, and they were both obese. Nevertheless, I met a couple of other pupils who were obese but were nonetheless not bullied. In fact, one of those who bullied Anna was Pete in her class, and as I could observe, he and Anna had a very similar body size. In contrast to her, he belonged to the popular group of boys in the class. He was tall, obese and had a reputation for being 
physically strong. His body size probably reinforced the impression that he was strong and powerful. Pete was also a kind of 'clown' in the class, who often made jokes and got others, including himself, to laugh. He could be very assertive and was rather prone to defend his friends, but also others in random, when they were physically or verbally attacked.

Whereas Anna and Evelina were bullied, Pete and some other obese children were not. At least two explanations could be given. First, the children used both macro-level cultural norms and categories as well as more micro-level and locally constructed norms and categories in a selective and creative way in order to produce both fitting and misfitting. Hence, there was a flexible use of societal normativities and local peer norms in bullying. The macro-level fat-phobic norm (Lupton 2013) was selectively adopted to bully and thus misfit Anna and Evelina but not Pete. In fact, Pete himself sometimes used this fat-phobic norm to mock Anna. The selective and flexible use of normativities should not be confused with a free or voluntarist notion. Butler (1993) argues that performativity is not a 'free play'. It is impelled and sustained by constraints and shaped by discursive regimes. Neither can we reduce misfitting to discursive determinism. Butler $(1990,195)$ emphasizes that to be constituted by discourse is not the same as 'to be determined by discourse, where determination forecloses the possibility of agency'. According to the new sociology of childhood (Prout and James 1997), children are not just passive recipients, but active agents in their socialisation process. They are both constrained by structure and at the same time active agents acting in and upon structure. Corsaro (2005, 18-19) argues that 'children create and participate in their own unique peer cultures by creatively taking or appropriating information from the adult world to address their own peer concerns'. Children's use of normativities occurred in the interplay between the adult world and the peer culture, between structure and agency.

Secondly, the creative and selective use of normativities in bullying reveals a situated and fluid co-construction of intersectionality. One important difference between the obese Pete and the two obese girls was the fact that Pete was a boy whereas Anna and Evelina were girls. Although Pete was threatened by the presence of the fat-phobic discursive practice among the pupils in school - which plagued Anna and Evelina - he efficiently used privileges so as to avoid marginalisation, fit into the peer landscape, and be included in a high-status peer group of boys in his class. Butler $(1990,25)$ argues that gender is 'performatively constituted by the very "expressions” which are said to be its results'. Gender identities, categories, differences and power asymmetries are socially constructed through the continual performances of particular discourses. As in other ethnographic studies (e.g. Thorne 1993), when analysing gender norms in these school classes, an ideal boy was a child who was tough, physically strong, and good at sports, whereas an ideal girl was a child who was gentle, good-looking, sensitive and affectionate. However, there was an exception in two school classes located in the social disadvantaged, multi-ethnic low-class neighbourhood, in which being 'bitchy' and assertive were associated with a girl's popularity rather than being gentle and nice, but still together with beauty/attractiveness and fashionable clothes (cf. Reay 2001). Hence, obesity was a greater disadvantage for girls than for boys.

In accordance with previous ethnographic research (Adler and Adler 1998; Eder, Evans, and Parker 1995), toughness was used as a predominant method among boys to establish their position in the status hierarchy, and Pete was both tough and assertive. In contrast, good-looking physical appearance, including ideal body-size and the 'right' clothing, was the predominant norm for popularity among the girls (cf. Currie, Kelly, and Pomerantz 2007). This was emphasized by both girls and boys in my interviews with them.

Robert: Who are the most popular boys in the class?

Ahmed: $\quad$ Simon, Muhammed, and I.

Robert: How come that you are the most popular boys in the class? 

Ahmed:
I don't know.
Robert: $\quad$ No, and you don't have to know for sure, but it's good enough if you tell me what you think.
Ahmed: Well, because we're cool. We're good at fighting. We're good at football.
Robert: $\quad$ And what about the girls? Who are the most popular girls in the class?
Ahmed: $\quad$ Alva and Sarah.
Robert: How come?
Ahmed: $\quad$ Well, because-, I mean, all boys think that Alva is the prettiest in the class, and since Sarah is Alva's best friend, she becomes popular because of that. And they wear brand clothing.
(Interview with a boy in Grade 4)

In one of the fifth-grade classes, two popular girls explained to me that they were popular because they were good-looking (even though they smiled and looked a little embarrassed when they told me that), wore the 'right' clothes and hung around with the popular boys in their class as well as with a couple of popular boys in the sixth grade. Girls' popularity and their within-gender competition of popularity were here heteronormatively structured, in which girls' degree of good-looks was dependent on boys' evaluation and recognition. The most prevalent bullies in the cases of Anna and Evelina were in fact popular boys. Renold (2006) and Ringrose (2008) adopt Butler's (1990) concept the heterosexual matrix in their analyses of girls' social relations. In the current study, the heterosexual matrix and the 'boy gaze' seemed to be particularly important for understanding girls' popularity as well as when girls were victims of bullying in these cases. Although good-looking and fashionable clothing were among the popular markers for boys too in some of the classes, these were the most important popular markers for girls in all classes, whereas toughness, athletic skills and coolness were much more important popular markers for boys. Here body size and gender intersected, which made Anna as an obese girl vulnerable to the social process of misfitting. Evelina, in turn, told me that she was bullied for three reasons.

\footnotetext{
Evelina: It's because I'm fat and I have ADHD, and because of the colour of my skin. Robert: $\quad$ Colour of your skin?

Evelina: $\quad$ Yes, they say that I have a pigskin.

(Interview with a Evelina in Grade 5)
}

These reasons were also usually referred to when other classmates explained why this bullying was going on in their class. Once again, being obese collided with gender norms of the ideal girl connected with the widespread fat-phobic discourse and beauty ideals. Furthermore, both Evelina and other children associated her ADHD with her angry outbursts, also in conflict with the ideal girl norms. It was also co-constructed among peers as 'there's something wrong with her brain' (Simon, Grade 5). In addition, the school was located in a social disadvantaged multi-cultural neighbourhood. Only a small minority of the classmates had a Swedish ethnic background, whereas the vast majority had a non-European ethnic background (mainly from the Middle-East and North Africa). One of the teachers reported that, 'there are some problems with reverse racism in this neighbourhood, which we also have noticed in the school' (Karin, teacher in Grade 5). Teasing Evelina for having a 'pigskin' was an expression of this reverse racism. Several pupils, mostly boys but also some girls, were involved in this bullying, but the pupil who was recurrently identified among the classmates as the most notorious bully was Daniel. The surprising fact in this case, however, was that like Evelina, Daniel had a Swedish ethnic background (white skin) and the diagnosis ADHD (with even more angry outbursts). To his advantage though, he was a boy, tough, good at 
sport, not obese at all, and considered among his classmates as being strong and goodlooking.

Previous research has shown that pupils with disabilities and special educational needs (for a review, see Rose, Monda-Amaya, and Espelage 2011), including neuropsychiatric diagnoses such as ADHD (Fite et al. 2014; Holmberg and Hjern 2008; Taylor et al. 2010), are at higher risk of being bullied. In addition, the present study illustrates how a membership of the ADHD category could intersect with gender. Evelina's girlhood was constructed through her ethnicity, body size and ADHD diagnosis just as her body size was constructed through her gender, colour of skin and ADHD diagnosis. At the same time, her ADHD reputation was constructed through her girlhood, body size and ethnicity, and her ethnicity was constructed through her gender, body size, and ADHD diagnosis. Thus, not simply one power relation or social category, but different lines of oppression were interwoven in misfitting Evelina.

Moreover, 'athleticability' (i.e. being physically strong, motor skillful and good at sports) intersected with gender and was a powerful privilege for boys. In contrast to Pete and many other popular boys, both the long-term victims John in Grade 4 and Andy in Grade 5 were categorized by their classmates as being physically weak, clumsy and poor at sports. These descriptions (together with some other descriptions) were also used by their peers as explanations for bullying. Nevertheless, Frida in fifth grade was the most popular girl in her class. She was considered among her classmates as being nice, a high academic achiever and the best-looking girl in the class. At the same time, observations from physical education revealed that Frida displayed poor athletic skills (which she sometimes downplayed by smiling and giggling), but none of her classmates talked about that. In all these cases, bullying contributed to the regulation of masculinity and femininity by disciplining bystanders and the children involved to associate gender norm transgressions with misfitting and its social costs.

Bullying could be understood as what Ringrose and Renold (2010) called normative cruelties in which various normativities intersected through situated and changeable patterns of social interactions in everyday school life. Whereas Daniel got away with his ADHD diagnosis, Anna and Evelina were repeatedly attacked because of their ADHD diagnosis. Evelina was a victim of reversed racist bullying intertwining with fat-phobic, physical appearance, disability and gender bullying. In contrast, Nada in the fourth grade located in the white, predominantly middle-class school was a target of racist bullying due to her African colour of skin intertwined with religious bullying due to her Muslim faith and clothing. Some of the popular boys in her class were identified as her main bullies. The reasons they gave for why they bullied her were that she was black, 'ugly', believed in Islam, and wearing a veil. She was defined by them as multi-deviant. Misfitting was once again the main theme.

Worrisome though and similar to what Myers and Bhopal (2015) found, in this context of white privilege and hegemonic whiteness, Nada was not identified as a victim of racism (or a victim of Islamophobia) by her teacher. Instead, her teacher attributed the bullying to the boys' bad manners, and in particular to one of the boy's - Samuel's - strong aggressive tendencies. The teacher's perspective reflected a predominant bully discourse (Ringrose and Renold 2010) that tends to conceptualize and reduce the problems of bullying in terms of individual or family dysfunction, deficits, or pathology - a discourse that has been criticized by several scholars (Bansel et al. 2009; Canty et al. 2016; Ellwood and Davies 2010; Horton 2011, 2016a; Ringrose and Renold 2010). Still, Samuel had a long record of aggression and fighting, which seemed to have rewarded him with a dominant social status and a strong position in the popular boy group. This illustrates the complex interplay between individual and contextual factors (Espelage and Swearer 2004; Migliaccio and Raskauskas 2015; Thornberg 2015b). Bullying in the long-term bullying cases was a goal-oriented behaviour to gain and maintain power and social status (Volk Dane, and Marini 2014), in which certain normativities were used and reinforced. In addition, the long-term victim John in Grade 4 was 
not only socially categorized as physically weak, clumsy and poor at sports. He also had learning difficulties that became visible in the classroom and this was an additional bullying reason mentioned among his classmates. Nevertheless, there were a couple of other classmates who also displayed learning difficulties in the very same class but without being long-termed bullied. Normativities were selectively used and intersected.

Robert: $\quad$ Can you help me understand what is going on? You are telling me that you are bullying John because he so dumb that he needs help from Gunilla [special educator]. But why do you only pick on him and not the others who need to go to Gunilla too?

Viggo: $\quad$ I have no problems with David and Tom. They're OK.

Robert: $\quad$ Why are they OK and not John?

Viggo: They're not weird like him. And they're good at football. You've been here for a while so you know that quite a few of the boys in our class play football a lot during the breaks.

(Interview with a boy in Grade 4)

In all the examined cases, bullying seemed to maintain one or several normative moral orders (Ellwood and Bronwyn 2010) in the specific situation and particular context, and thus targeted those who failed to meet certain norms that were negotiated among the peers to be correct 'in group' manners. There were simultaneous and interacting experiences of oppressions based on gender norms, appearance (including physical beauty - ugliness, body size, and clothing), ethnicity, (dis)ability, '(dis)athleticability', social class, religion, and other more locally constructed peer norms. From a sociological point of view, the analysis portrayed an interplay between agency and structure in which pupils selectively and creatively appropriated norms and categories in their everyday interactions (cf. Corsaro 2005), sometimes resulting in short-term bullying and sometimes in long-term bullying in which various normativities from the macro-, meso-, and micro-level intersected and produced a patterned fluidity (Richardson 2007) of misfitting. In accordance with Marfelt's (2016) methodological approach, 'grounded intersectionality', this finding was empirically grounded in the current study by getting close to the research subjects and their everyday interactions and experiences, and by relying on collective actions as the primary analytic starting point rather than a priori adopting a macro-analytical perspective. As Glaser (1978) would had put it, these theoretical constructs fit with the data and have earned their way into the analysis and this grounded theory of misfitting in bullying through my iterative and abductive use of literature in relation to data, coding and analysis (Thornberg 2012).

\section{Conclusions}

In accordance with a constructivist position of grounded theory, I do not claim to offer an exact picture, but rather an interpretative portrayal (Charmaz 2014) of school bullying. Nevertheless, this portrayal paints a picture of the core process of misfitting in bullying, and how this collective process involved a creative and selective use of normativities from the macro-, meso-, and micro-level. Our theoretical understanding of bullying cannot be confined to individual characteristics, although they play a part too in the complex interplay between contextual and individual factors, as stated in the social-ecological framework (e.g. Espelage and Swearer 2004; Migliaccio and Raskauskas 2015). The current findings indicate a huge overlap between bullying and discrimination. There is a widespread and predominant bully discourse deployed in school policy and practice in which bullying is conceptualized as caused by bullies' and victims' individual characteristics (Ringrose and Renold 2010). This predominant discourse not only makes teachers and others blind to gender norms, heteronormativity, racism and a range of other oppressions taking place in bullying, but will fail to offer an appropriate knowledge base on how to counteract and reduce bullying. 
I have used the terms 'bullies' and 'victims' in the present study simply because these are the terms used in the data, in other words, among the teachers and pupils in the actual schools. However, at the same time, the findings demonstrate how inappropriate it is to adopt these terms in school policies and everyday school practices. These broad binary categories (a) obscure the individual variation and possible sub groups of 'bullies' and 'victims', (b) risk labelling, pathologizing, and stigmatizing certain pupils, (c) risk portraying a rather static picture of the social dynamics of bullying and peer group processes, and (d) draw the attention away from broader contextual factors such as school culture, discursive practices, social identities, gender norms, racism, disability discrimination, heteronormativity, body discrimination and other hegemonies. Anti-bullying policies and practices have to include a critical pedagogy and focus on social interaction patterns, peer cultures, social hierarchies, power dynamics, cultural norms, hegemonies and intersectionality rather than labelling and pathologizing involved pupils. As has been demonstrated, school bullying is situated and embedded in social and political contexts and 'within-child' explanations will never capture the full complexity and the fluid connections to various normativities, privileges and discriminations when misfitting is co-constructed in bullying.

In school, teachers have to make pupils critically aware of taken-for-granted norms and how these constitute and are constituted in their everyday social interactions. Butler $(1990,34)$ points to the 'challenge for rethinking gender categories outside of the metaphysics' that naturalizes these categories. To counteract bullying, schools need to educate pupils to challenge oppressive discursive regimes and performativities - gender norms and heteronormativity as well as all kinds of oppressive normativities. Normative constraints that repetitively constitute misfitting in bullying ought to be 'understood as generative political structures rather than naturalized foundations' (Butler, 1990, 201). On the national, local community, school and classroom levels, more political, social and educational work is needed to challenge oppressive and discriminating discourses and to promote social justice and the value of diversity. Anti-bullying work has to be recognized as a part of these political and social reforms and interventions.

\section{Acknowledgement}

This work was supported by the Swedish Research Council under Grant 2008-5548 and Grant 2013-7753.

\section{References}

Adler, P. A., and P. Adler. 1998. Peer Power: Preadolescent Culture and Identity. New Brunswick: Rutgers University Press.

Author (2015).

Bansel, P., B. Davies, C. Laws, and S. Linnell. 2009. "Bullies, Bullying and Power in the Context of Schooling.” British Journal of Sociology of Education 30 (1): 59-69.

Bibou-Nakou, I., J. Tsiantis, H. Assimopoulos, P. Chatzilambou, and D. Giannakopoulou. 2012. "School Factors Related to Bullying: A Qualitative Study of Early Adolescent Students.” Social Psychology of Education 15 (2): 125-145.

Blumer H. 1969. Symbolic Interactionism. Berkeley, CA: University of California Press.

Bosacki, S. L., Z. A. Marini, and A. V. Dane. 2006. "Voices from the Classroom: Pictorial and Narrative Representations of Children's Bullying Experiences.” Journal of Moral Education 35 (2): 231-245.

Butler, J. 1990. Gender Trouble: Feminism and the Subversion of Identity. New York: Routledge.

Butler, J. 1993. Bodies that Matter: On the Discursive Limits of "Sex". New York: Routledge. 
Canty, J., M. Stubbe, D. Steers, and S. Collings. 2016. "The Trouble with Bullying Deconstructing the Conventional Definition of Bullying for a Child-Centred Investigation into Children’s Use of Social Media.” Children \& Society, 30 (1): 48-58.

Charmaz, K. 2014. Constructing Grounded Theory. 2nd ed. London: Sage.

Corsaro, W. A. (2005). The Sociology of Childhood. 2nd ed. Thousand Oaks: Pine Forge Press.

Currie, D., D. Kelly, and S. Pomerantz. 2007. ““The Power to Squash People’: Understanding Girls’ Relational Aggression.” British Journal of Sociology of Education 28 (1): 23-37.

Dixon, R., P. Smith, and C. Jenks. 2004. "Bullying and Difference: A Case Study of Peer Group Dynamics in One School.” Journal of School Violence 3 (4): 41-58.

Eder, D., C. C. Evans, and S. Parker. 1997. School Talk: Gender and Adolescent Culture. New Brunswick, NJ: Rutgers University Press.

Ellwood, C., and Davies, B. (2010). "Violence and the Moral Order in Contemporary Schooling: A Discursive Analysis." Qualitative Research in Psychology 7 (2): 85-98.

Espelage, D. L., and S. M. Swearer, eds. 2004. Bullying in American Schools: A SocialEcological Perspective on Prevention and Intervention. Mahwah, NJ: Lawrence Erlbaum Associates.

Fite, P. J., S. C. Evans, J. L. Cooley, and S. L. Rubens. 2014. "Further Evaluation of Association between Attention-Deficit/Hyperactivity and Oppositional Defiant Disorder Symptoms and Bullying-Victimization in Adolescence.” Child Psychiatry and Human Development 45 (1): 32-41.

Glaser, B. G. 1978. Theoretical Sensitivity. Mill Valley, CA: Sociology Press.

Glaser, B. G., and A. L. Strauss. 1967. The Discovery of Grounded Theory. New York: Aldine de Gruyter.

Hammersley, M., and P. Atkinson. 2007. Ethnography: Principles in Practice. 3th ed. London: Routledge.

Hewitt, J. P., and D. Shulman. 2011. Self and Society: A Symbolic Interactionist Social Psychology. 11th ed. Boston; MA: Pearson.

Holmberg, K., and A. Hjern. "Bullying and Attention-Deficit-Hyperactivity Disorder in 10Years-Olds in a Swedish Community.” Developmental Medicine \& Child Neurology 50 (2): 134-138.

Hong, J. S., and D. L. Espelage. 2012. "A Review of Research on Bullying and Peer Victimization in School: An Ecological System Analysis.” Aggression and Violent Behavior 17 (4): 311-322.

Horton, P. 2011. "School Bullying and Social and Moral Orders.” Children \& Society 25 (4): $268-277$.

Horton, P. 2012. Bullied into it: Bullying, Power and the Conduct of Conduct. Stroud: E\&E Publishing.

Horton, P. 2016a. "Portraying Monsters: Framing School Bullying through a Macro Lens.” Discourse: Studies in the Cultural Politics of Education 37 (2): 204-214.

Horton, P. 2016b. "Unpacking the Bullying Doll: Reflections from a Fieldwork at the SocialEcological Square.” Confero: Essays on Education, Philosophy and Politics 4 (1), 71 95.

Jimerson, S. R., S. M. Swearer, and D. L. Espelage, eds. 2010. Handbook of Bullying in Schools: An International Perspective. New York, NY: Routledge.

Kousholt, K., and T. B. Fisker. 2015. "Approaches to Reduce Bullying in Schools - a Critical Analysis from the Viewpoint of First- and Second-Order Perspectives on Bullying.” Children \& Society 29 (6): 593-603.

Lupton, D. 2013. Fat. London: Routledge. 
Marfelt, M. M. 2016. “Grounded Intersectionality: Key Tensions, a Methodological Framework, and Implications for Diversity Research.” Equality, Diversity and Inclusion: An international Journal 35 (1): 31-47.

Migliaccio, T. 2015. "Teacher Engagement with Bullying: Managing an Identity within a School.” Sociological Spectrum 35 (1): 84-108.

Migliaccio, T., and J. Raskauskas, J. 2015. Bullying as a Social Experience: Social Factors, Prevention and Intervention. Farnham: Ashgate.

Mishna, F., M. Saini, and S. Solomon. 2009. “Ongoing and Online: Children and Youth's Perceptions of Bullying.” Children and Youth Services Review 31 (12): 1222-1228.

Myers, M., and K. Bhopal. 2015. "Racism and Bullying in Rural Primary Schools: Protecting White Identities Post Macpherson.” British Journal of Sociology of Education. Advance online publication. doi: 10.1080/01425692.2015.1073099.

Prout, A. and J. James. 1997. "A New Paradigm for the Sociology of Childhood? Provenance, Promise and Problems.” In Constructing and Reconstructing Childhood. 2nd ed., edited by J. Allison and A. Prout, 7-33. London: The Falmer Press.

Reay, D. 2001. "Spice Girls, Nice Girls, Girlies and Tomboys - Gender Discourses, Girls' Cultures and Femininities in the Primary Classroom." Gender and Education 13 (2): 153-166.

Renold, E. 2006. “'They Won't Let Us Play ... Unless You're Going Out with One of Them': Girls, Boys and Butler's 'Heterosexual Matrix' in the Primary Years. British Journal of Sociology of Education 27 (4): 489-509.

Richardson, D. 2007. "Patterned Fluidities: (Re)imagining the Relationship between Gender and Sexuality.” Sociology 41 (3): 457-474.

Ringrose, J. (2008). “'Just Be Friends': Exploring the Limits of Educational Bully Discourses for Understanding Teen Girls’ Heterosexualized Friendships and Conflicts.” British Journal of Sociology of Education 29 (5): 509-522.

Ringrose, J., and Renold, E. (2010). "Normative Cruelties and Gender Deviants: The Performative Effects of Bully Discourses for Girls and Boys in School.” British Educational Research Journal 36 (4): 573-596.

Rose, C. A., L. E. Monda-Amaya, and D. L. Espelage. 2011. "Bullying Perpetration and Victimization in Special Education: A Review of the Literature.” Remedial and Special Education 32 (2): 114-130.

Salmivalli, C. 2010. "Bullying and the Peer Group: A Review.” Aggression and Violent Behavior 15 (2): 112-120.

Schatzman, L., and A. L. Strauss. 1973. Field Research: Strategies for a Natural Sociology. Englewood Cliffs, NJ: Prentice-Hall.

Schott, R. M., and D. M. Søndergaard, eds. 2014. School Bullying: New Theories in Context. Cambridge: Cambridge University Press.

Søndergaard, D. M. 2012. "Bullying and Social Exclusion Anxiety in Schools.” British Journal of Sociology of Education 33 (3): 355-372.

Taylor, L. A., C. Saylor, K. Twyman, and M. Macias. 2010. “Adding Insult to Injury: Bullying Experiences of Youth with Attention Deficit Hyperactivity Disorder.” Children's Health Care 39 (1): 59-72.

Teräsahjo, T. and C. Salmivalli. 2003. "'She Is Not Actually Bullied': The Discourse of Hharassment in Student Groups.” Aggressive Behavior 29 (2): 134-154.

Thornberg, R. 2010. “Schoolchildren’s Social Representations on Bullying Causes.” Psychology in the Schools 47 (4): 311-327.

Thornberg, R. 2012. “Informed Grounded Theory.” Scandinavian Journal of Educational Research 56 (3): 243-259. 
Thornberg, R. (2015a). "School Bullying as a Collective Action: Stigma Processes and Identity Struggling.” Children and Society 29 (4): 310-320.

Thornberg, R. (2015b). “The Social Dynamics of School Bullying: The Necessary Dialogue between the Blind Men around the Elephant and the Possible Meeting Point at the Social-Ecological Square." Confero: Essays in Education, Philosophy and Politics 3 (2): 161-203.

Thorne, B. 1993. Gender Play: Girls and Boys in School. Buckingham: Open University Press.

Volk, A. A., A. V. Dane, and Z. A. Marini. 2014. "What Is Bullying? A Theoretical Redefinition.” Developmental Review 34 (4): 327-353.

Weinstock, J., and M. Krehbiel. 2009. "Fat Youth as Common Targets for Bullying.” In The Fat Studies Reader, edited by E. Rothblum, and S. Solovay, 120-126. New York: New York University Press. 